\title{
Study of Self Assembly Systems Formed by Malic Acid and Alkyloxy Benzoic Acids
}

\author{
Vellalapalayam Nallagounder Vijayakumar and Mathukumalli Lakshmi Narayana Madhu Mohan \\ Liquid Crystal Research Laboratory (LCRL), Bannari Amman Institute of Technology, \\ Sathyamangalam 638 401, India \\ Reprint requests to M.L.N.M. M.; E-mail: mln.madhu@gmail.com
}

Z. Naturforsch. 65a, 1156 - 1164 (2010); received February 4, 2010 / revised April 30, 2010

\begin{abstract}
Self assembly systems formed by malic acid and alkyloxy benzoic acids are characterized. The ferroelectric ingredient malic acid formed double hydrogen bond with $p$ - $n$-alkyloxy benzoic acids. Various hydrogen bonded complexes have been synthesized with malic acid and pentyl to dodecyloxy benzoic acid, respectively. Fourier transformation infrared (FTIR) studies confirm the hydrogen bond formation. Polarizing optical microscopic (POM) studies revealed the textural information while the transition and enthalpy values are calculated from differential scanning calorimetry (DSC) studies. A phase diagram has been constructed from the POM and DSC studies. A new smectic ordering, smectic $\mathrm{X}^{*}$, has been identified which exhibits a finger print type texture. This phase has been characterized by POM, DSC, helix, and tilt angle studies. The transition from traditional cholesteric to smectic $\mathrm{X}^{*}$ phase is observed to be first order. The tilt angle data in this phase has been fitted to a power law and the temperature variation of the tilt angle follows mean field theory predictions. The results of FTIR, POM, DSC, tilt angle, and helicoidal studies are discussed.
\end{abstract}

Key words: Malic Acid; p-n-Alkyloxy Benzoic Acid; Smectic X* Ordering.

\section{Introduction}

Since the discovery of the first ferroelectric liquid crystal by Meyer et al. [1] interest on these soft materials have grown enormously. In the recent times hydrogen bonded liquid crystals (HBLC) [2-13], are designed and synthesized from materials selected on the basis of their molecular reorganization and self assembly capability. The applicational aspects [1418] and commercial viabilities made many research groups to work on these soft materials. Hydrogen bonded liquid crystalline materials are known since early $1960[3,4]$, however, in the recent times much work has been done on these complexes [5-13,1922]. A hydrogen bond enables various mesogenic and non-mesogenic compounds to form complexes which exhibit rich phase polymorphism. HBLC usually are composed of a proton donor and acceptor molecules. The reported data $[5-12,19-22]$ indicate the fact that if the HBLC materials are mesogenic, it is enough if one of the proton donor or an acceptor molecule exhibits mesogenic property. The chemical molecular structure [19-22] of HBLC is co-related to the physical properties exhibited by it.

The reported literature $[2,7,10,13-21]$ suggests the formation of HBLC through carboxylic acids as well as from mixtures of unlike molecules capable of interacting through $\mathrm{H}$-bonding. Usually in all these HBLC the rigid core is made up of covalent and noncovalent hydrogen bonding. The discovery of hydrogen bonded liquid crystals by Kato and Frechet [14] opened a new chapter in synthesis, design, and characterization of these mesogens which facilitated many research groups to work in this field [23-32].

With our previous experience [23-26,33-46] in designing and synthesizing liquid crystals, and in continuation of our efforts to understand hydrogen bonded mesogens in the present work a successful attempt has been made to design and isolate a homologous series of hydrogen bonded ferroelectric liquid crystals (HBFLC). The mesogenic $p$ - $n$-alkyloxy benzoic acids (where $n$ represents the alkyloxy carbon number from 5 to 12) formed a hydrogen bond ferroelectric liquid crystal with malic acid, respectively. Phase diagrams, mesogenic phase, and thermal range are discussed.

\section{Experimental}

Optical textural observations were made with a Nikon polarizing microscope equipped with a Nikon digital CCD camera system with 5 mega pixels and 
Table 1. Transition temperatures obtained by different techniques. Enthalpy values (J/g) given in parenthesis.

\begin{tabular}{|c|c|c|c|c|c|c|c|c|c|}
\hline Carbon & Phase variance & Technique & Crystal to Melt & $\mathrm{Ch}$ & $\mathrm{X}^{*}$ & $\mathrm{C}^{*}$ & $\mathrm{~F}^{*}$ & $\mathrm{G}^{*}$ & Crystal \\
\hline \multirow[t]{3}{*}{5} & $\mathrm{~F}^{*}$ & DSC (h) & $124.3(57.68)$ & & & & $141.5(13.43)$ & & \\
\hline & & $\operatorname{DSC}(\mathrm{c})$ & & & & & $136.8(9.68)$ & & 112.7 (66.59) \\
\hline & & POM (C) & & & & & 137.5 & & 113.2 \\
\hline \multirow[t]{3}{*}{6} & $\mathrm{~F}^{*}$ & $\overline{\mathrm{DSC}(\mathrm{h})}$ & $69.6(47.0)$ & & & & $80.6(50.61)$ & & \\
\hline & & $\operatorname{DSC}(\mathrm{c})$ & & & & & $\begin{array}{l}94.1 \text { Merged } \\
\text { with crystal }\end{array}$ & & $81.5(64.43)$ \\
\hline & & POM (C) & & & & & 94.6 & & 81.9 \\
\hline \multirow[t]{3}{*}{7} & Ch F* & $\overline{\mathrm{DSC}}(\mathrm{h})$ & $92.6(72.6)$ & \# & & & $\begin{array}{l}\text { Merged } \\
\text { with melt }\end{array}$ & & \\
\hline & & $\mathrm{DSC}(\mathrm{c})$ & & $130.3(3.63)$ & & & 84.5 (28.49) & & $71.3(34.54)$ \\
\hline & & POM (C) & & 130.9 & & & 84.9 & & 71.8 \\
\hline \multirow[t]{3}{*}{8} & Ch $X^{*} \mathrm{C}^{*} \mathrm{~F}^{*}$ & DSC (h) & $76.9(62.64)$ & $146.7(2.32)$ & \# & \# & $\#$ & & \\
\hline & & $\mathrm{DSC}(\mathrm{c})$ & & $140.9(2.02)$ & $137.3(3.53)$ & $99.6(3.94)$ & 91.7 (38.43) & & $52.2(46.99)$ \\
\hline & & POM (C) & & 141.3 & 137.7 & 100.0 & 92.1 & & 52.5 \\
\hline \multirow[t]{3}{*}{9} & Ch $X^{*} C^{*} F^{*}$ & $\overline{\mathrm{DSC}}(\mathrm{h})$ & $94.3(71.71)$ & \# & $127.3(0.91)$ & $113.8(2.84)$ & \# & & \\
\hline & & $\operatorname{DSC}(\mathrm{c})$ & & $134.5(4.36)$ & $124.5(9.40)$ & $110.1(1.35)$ & $87.7(21.88)$ & & $66.3(46.52)$ \\
\hline & & POM (C) & & 134.9 & 124.9 & 110.6 & 91.1 & & 66.6 \\
\hline \multirow[t]{3}{*}{10} & Ch $X^{*} \mathrm{C}^{*} \mathrm{~F}^{*}$ & $\overline{\mathrm{DSC}}(\mathrm{h})$ & $86.23(29.08)$ & \# & $132.2(0.65)$ & \# & $95.5(14.90)$ & & \\
\hline & & $\operatorname{DSC}(\mathrm{c})$ & & $134.5(0.77)$ & $131.7(0.26)$ & $118.6(1.74)$ & $89.2(10.37)$ & & 69.4 (15.34) \\
\hline & & POM (C) & & 134.9 & 132.1 & 119.0 & 89.6 & & 69.7 \\
\hline \multirow[t]{3}{*}{11} & Ch $X^{*} C^{*} F^{*} G^{*}$ & DSC (h) & $100.0(94.63)$ & \# & $131.8(1.50)$ & $123.8(0.15)$ & \# & \# & \\
\hline & & $\operatorname{DSC}(\mathrm{c})$ & & $133.1(2.28)$ & $130.6(0.48)$ & $121.1(3.8)$ & $81.3(25.03)$ & 69.5 (17.99) & $53.6(40.2)$ \\
\hline & & POM (C) & & 133.5 & 130.9 & 121.5 & 81.6 & 69.8 & 53.9 \\
\hline \multirow[t]{3}{*}{12} & Ch $X^{*} C^{*} F^{*} G^{*}$ & DSC (h) & $96.1(101.29)$ & $136.9(1.59)$ & $131.6(0.33)$ & $\#$ & $\#$ & $\#$ & \\
\hline & & $\operatorname{DSC}(\mathrm{c})$ & & $131.0(2.93)$ & $\begin{array}{l}126.1 \text { Merged } \\
\text { with } C^{*}\end{array}$ & $125.0(1.13)$ & $83.0(19.72)$ & $66.9(9.46)$ & $47.1(24.07)$ \\
\hline & & $\operatorname{POM}(\mathrm{C})$ & & 131.4 & 126.5 & 125.3 & 83.3 & 67.3 & 47.4 \\
\hline
\end{tabular}

\# Monotropic transition; (h) Heating run; (c) Cooling run.

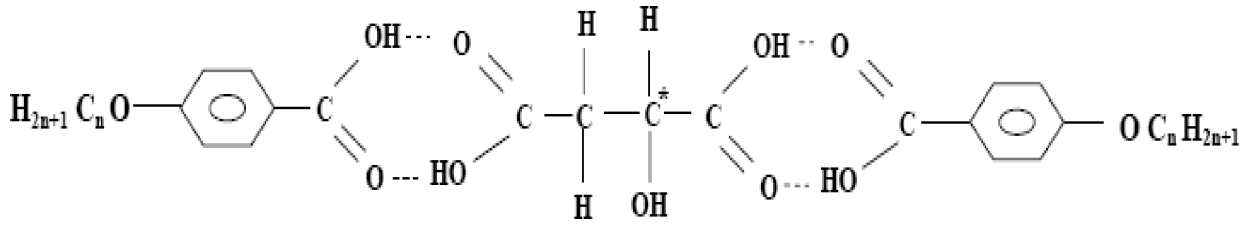

Fig. 1. Molecular structure of malic acid and alkyloxy benzoic acid hydrogen bonded complex.
$2560 \times 1920$ pixel resolution. The liquid crystalline textures were processed, analyzed, and stored with the aid of an ACT-2U imaging software system. The temperature control of the liquid crystal cell was equipped by Instec HCS402-STC 200 temperature controller (Instec, USA) to a temperature resolution of $\pm 0.1{ }^{\circ} \mathrm{C}$. This unit is interfaced to the computer by IEEESTC 200 to control and monitor the temperature. The liquid crystal sample is filled by capillary action in its isotropic state into a commercially available (Instec, USA) polyamide buffed cell with 4 micron spacer. An optical extinction technique was used for the determination of the tilt angle. The transition temperatures and corresponding enthalpy values were obtained by DSC (Shimadzu DSC-60). FTIR spectra was recorded (ABB FTIR MB3000) and analyzed with the MB3000 software. The $p$ - $n$-alkyloxybenzoic acids (nBA) and malic acid were supplied by Sigma Aldrich, Germany, and all the solvents used were E. Merck grade.

\subsection{Synthesis of HBFLC}

Intermolecular hydrogen bonded ferroelectric mesogens are synthesized by the addition of two moles of $p$ $n$-alkyloxybenzoic acids (nBA) with one mole of malic acid in N,N-Dimethyl formamide (DMF), respectively. Further, they are subject to constant stirring for $12 \mathrm{~h}$ at ambient temperature of $30{ }^{\circ} \mathrm{C}$ till a white precipitate in a dense solution is formed. The white crystalline crude complexes so obtained by removing excess DMF are then recrystallized with dimethyl sulfoxide (DMSO) and the yield varied from $85 \%$ to $95 \%$. Yield of higher homologues complexes are observed to be more compared to its lower counterparts. The 


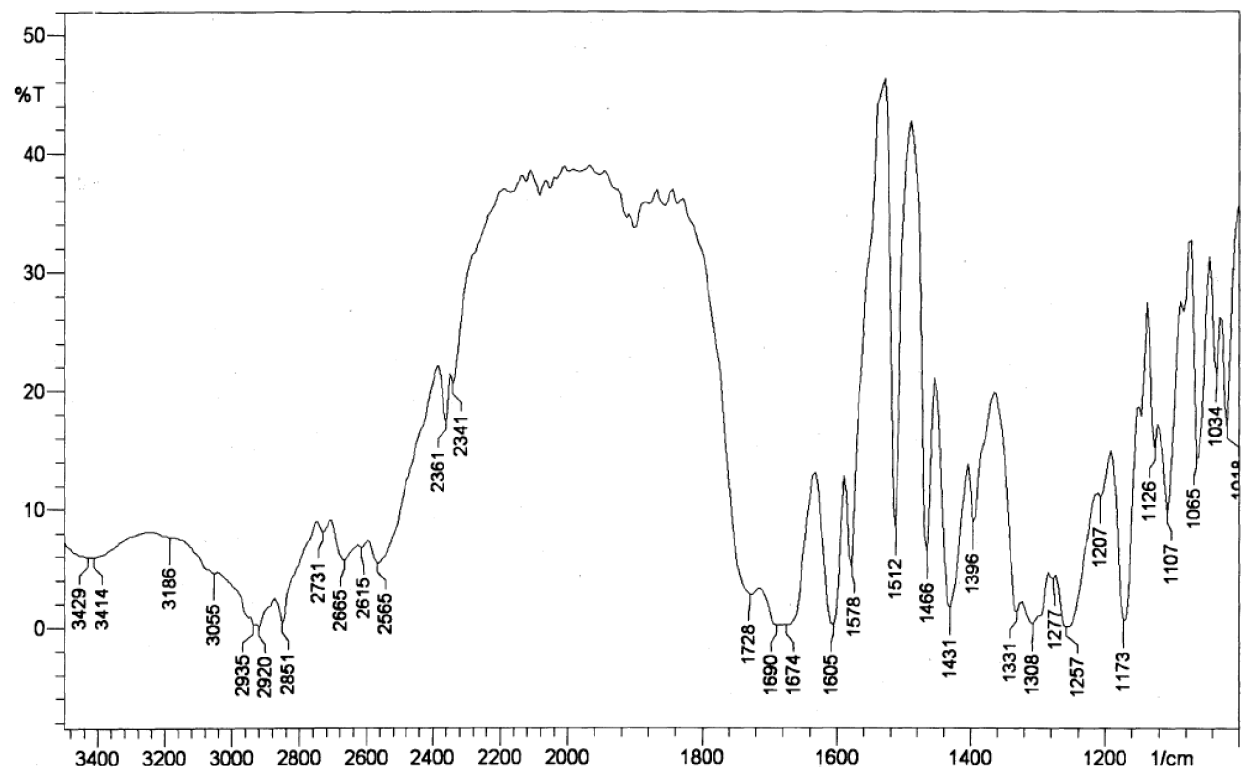

Fig. 2. FTIR spectra of MA+9BA complex. molecular structure of the present homologous series of $p$ - $n$-alkyloxybenzoic acids with malic acid is depicted in Figure 1, where n represents the alkyloxy carbon number. From this figure, the alternate hydrogen bonded sites along with a chiral carbon can be identified.

\section{Results and Discussion}

All the mesogens isolated under the present investigation are white crystalline solids and are stable at room temperature. They are insoluble in water and sparingly soluble in common organic solvents such as methanol, ethanol, benzene, and dichloro methane. However, they show a high degree of solubility in coordinating solvents like dimethyl sulfoxide (DMSO), dimethyl formamide (DMF), and pyridine. All these mesogens melt at specific temperatures below $150{ }^{\circ} \mathrm{C}$ (Table 1). They show high thermal and chemical stability when subjected to repeated thermal scans performed during POM and DSC studies.

\subsection{Phase Identification}

The observed phase variants, transition temperatures, and corresponding enthalpy values obtained by DSC in cooling and heating cycles for the MA+nBA complexes are presented in Table 1.

\subsection{MA+nBA Homologous Series}

The mesogens of the malic acid and alkyloxy benzoic acid ferroelectric homologous series are found to exhibit characteristic textures [47], viz., Cholesteric (threaded texture), smectic $\mathrm{X}^{*}$ (fingerprint texture), smectic $C^{*}$ (schlieren texture), smectic $\mathrm{F}^{*}$ (chequered board texture), and smectic $\mathrm{G}^{*}$ (multi colored mosaic texture), respectively. The general phase sequence of the malic acid and alkyloxy benzoic acids in the cooling run can be shown as:

$$
\begin{aligned}
& \text { Isotropic } \rightarrow \mathrm{SmF}^{*} \rightarrow \text { Crystal } \\
& (\mathrm{MA}+5 \mathrm{BA}),(\mathrm{MA}+6 \mathrm{BA}), \\
& \text { Isotropic } \rightarrow \mathrm{CH} \rightarrow \mathrm{SmF}^{*} \rightarrow \text { Crystal } \\
& (\mathrm{MA}+7 \mathrm{BA}), \\
& \text { Isotropic } \rightarrow \mathrm{CH} \rightarrow \mathrm{SmX}^{*} \rightarrow \mathrm{SmC}^{*} \rightarrow \mathrm{SmF}^{*} \\
& \rightarrow \text { Crystal } \\
& (\mathrm{MA}+8 \mathrm{BA}),(\mathrm{MA}+9 \mathrm{BA}),(\mathrm{MA}+10 \mathrm{BA}), \\
& \text { Isotropic } \rightarrow \mathrm{CH} \rightarrow \mathrm{SmX}^{*} \rightarrow \mathrm{SmC}^{*} \rightarrow \mathrm{SmF}^{*} \\
& \rightarrow \mathrm{SmG}^{*} \rightarrow \text { Crystal } \\
& (\mathrm{MA}+11 \mathrm{BA}),(\mathrm{MA}+12 \mathrm{BA}) \text {. }
\end{aligned}
$$

\subsection{Infrared Spectroscopy (FTIR)}

IR spectra of free $p$ - $n$-alkyloxybenzoic acid, malic acid, and their intermolecular H-bonded ferroelectric 
Table 2. Peak assignments of the FTIR data of alkoxy benzoic acid and hydrogen bonded complex.

\begin{tabular}{|c|c|c|c|}
\hline \multicolumn{2}{|c|}{$p$ - $n$-alkyloxybenzoic acid } & \multicolumn{2}{|c|}{ Hydrogen bonded complex } \\
\hline Peak & Assignment & Peak & Assignment \\
\hline $\begin{array}{l}1685 \text { and } \\
1695 \mathrm{~cm}^{-1}\end{array}$ & $\begin{array}{l}v(\mathrm{C}=\mathrm{O}) \\
\text { Conforms the } \\
\text { dimeric } \\
\text { nature }\end{array}$ & $\begin{array}{l}1690 \mathrm{~cm}^{-1} \\
\text { and absence } \\
\text { of } 1685 \text { and } \\
1695 \mathrm{~cm}^{-1}\end{array}$ & $\begin{array}{l}\text { Conforms the } \\
\text { monomeric nature }\end{array}$ \\
\hline $\begin{array}{l}\text { Absence of } \\
2935 \mathrm{~cm}^{-1}\end{array}$ & $\begin{array}{l}\text { Absence of } \\
v(\mathrm{O}-\mathrm{H}) \text { mode }\end{array}$ & $2935 \mathrm{~cm}^{-1}$ & $\begin{array}{l}v(\mathrm{O}-\mathrm{H}) \text { mode of } \\
\text { the the carboxylic } \\
\text { acid group }\end{array}$ \\
\hline
\end{tabular}

complexes are recorded in the solid state $(\mathrm{KBr})$ at room temperature. Figure 2 illustrates the FTIR spectra of the hydrogen bonded complex of MA+9BA in the solid state at room temperature as a representative case. Respective peaks and their assignments are listed in Table 2. Data in this table and the related literature $[20,22,48]$ strongly conform the formation of hydrogen bond and its existence in the monomeric form upon complexation.

\subsection{DSC Studies}

DSC thermograms are obtained in heating and cooling cycle. The sample is heated with a scan rate of $10{ }^{\circ} \mathrm{C} / \mathrm{min}$ and hold at its isotropic temperature for two minutes so as to attain thermal stability. The cooling run is performed with a scan rate of $10{ }^{\circ} \mathrm{C} / \mathrm{min}$. The respective equilibrium transition temperatures and corresponding enthalpy values of the mesogens of the homologous series are listed separately in Table 1. Polarizing optical microscopic studies also confirm these DSC transition temperatures.

\subsubsection{DSC Studies of $M A+5 B A$}

The phase transition temperatures and enthalpy values of pentyloxy benzoic acid and malic acid mesogen $(\mathrm{MA}+5 \mathrm{BA})$ are discussed. The DSC thermogram of MA+5BA is illustrated in Figure 3. From this figure and Table 1 it can be inferred that in the DSC heating run of the MA+5BA complex, two exothermic peaks are observed at $124.3{ }^{\circ} \mathrm{C}$ and $141.5{ }^{\circ} \mathrm{C}$ with enthalpy values of $57.68 \mathrm{~J} / \mathrm{g}$ and $13.43 \mathrm{~J} / \mathrm{g}$, respectively. These two peaks corresponds to the crystal to melt and melt to smectic $\mathrm{F}^{*}$ transitions. In the cooling run of this sample two peaks are observed at $136.8^{\circ} \mathrm{C}$ and $112.7^{\circ} \mathrm{C}$ with enthalpy values of $9.68 \mathrm{~J} / \mathrm{g}$ and $66.59 \mathrm{~J} / \mathrm{g}$, respectively. These endothermic peaks corresponds to isotropic to smectic $\mathrm{F}^{*}$ and smectic $\mathrm{F}^{*}$ to crystal transitions, respectively.

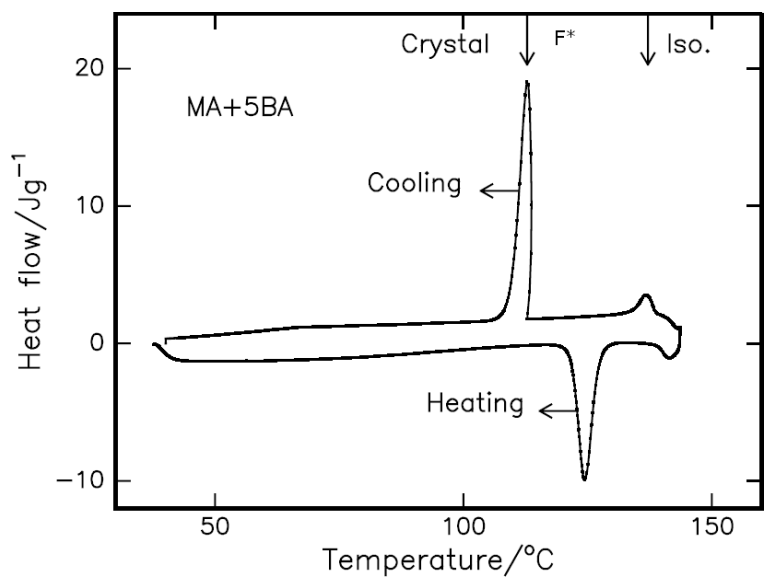

Fig. 3. DSC thermogram of MA+5BA complex.

\subsection{Phase Diagram of Pure p-n-Alkyloxybenzoic Acids}

The phase diagrams of pure $p$ - $n$-alkyloxybenzoic acids are reported [23] while the LTA+nBA homologous series are constructed through optical polarizing microscopic studies and by the phase transition temperatures observed in the cooling run of the DSC thermogram. The phase diagram of pure $p-n$ alkyloxybenzoic acid is reported [20,23] to be composed of two phases namely, nematic and smectic C.

\subsubsection{Phase Diagram of $M A+n B A$}

Phase diagram of malic acid and alkyloxy benzoic acids is depicted in Figure 4. The following points can be elucidated from this figure:

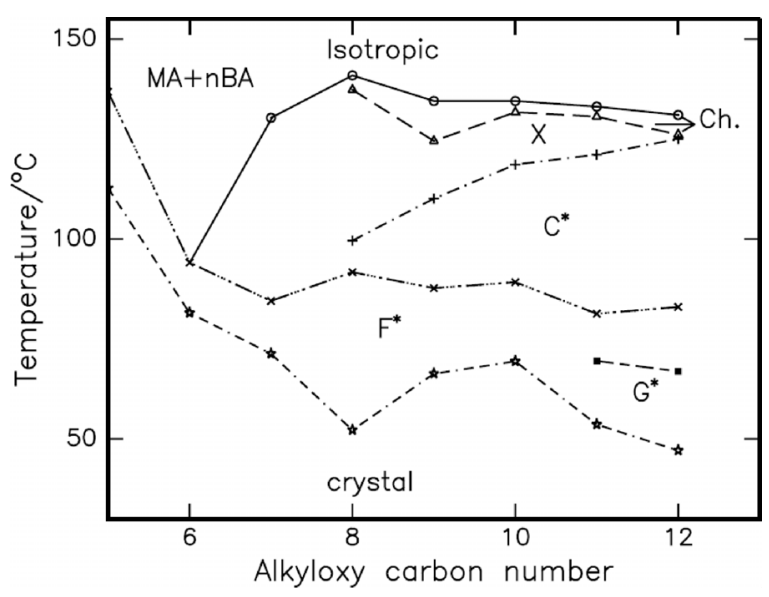

Fig. 4. Phase diagram of MA+nBA homologous series. 


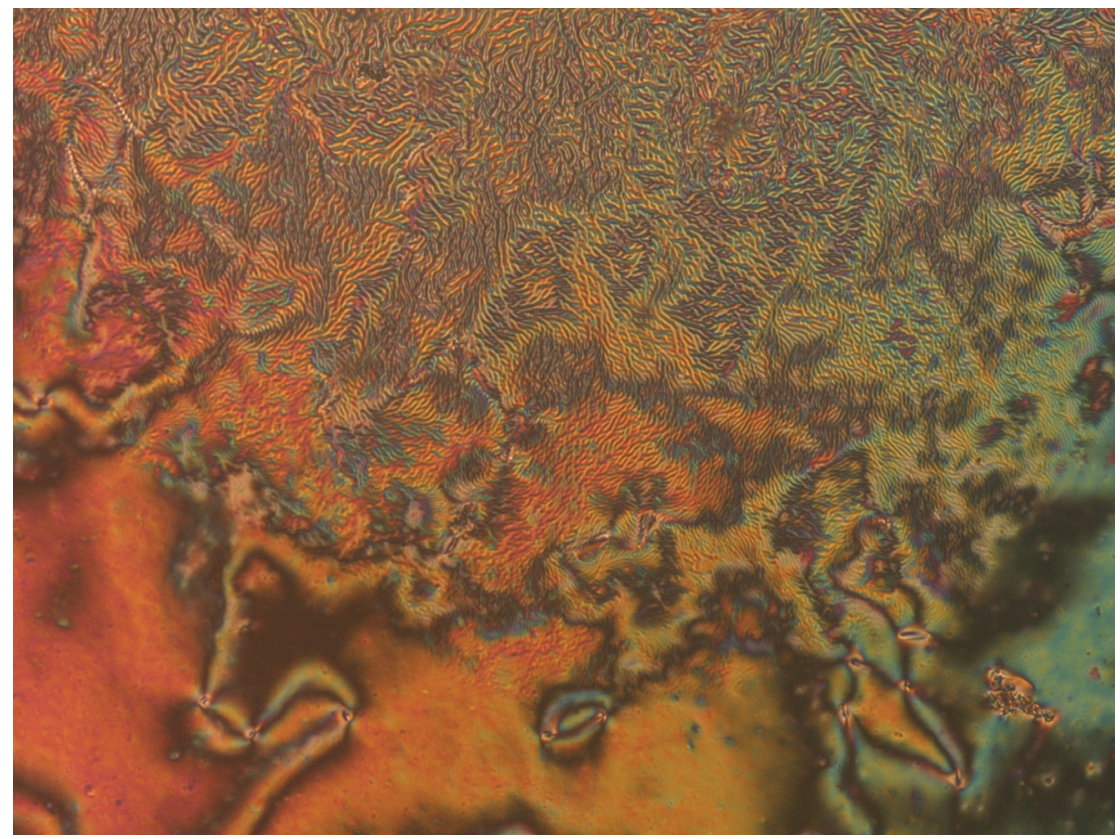

Plate 1a (colour online). Cholesteric to smectic $X^{*}$ phase transition in $\mathrm{MA}+8 \mathrm{BA}$ complex. i) The MA+nBA hydrogen bonded HBFLC homologous series exhibits four phases, namely, cholesteric, smectic $\mathrm{C}^{*}$, smectic $\mathrm{F}^{*}$, and smectic $\mathrm{G}^{*}$ phases along with a new phase identified as smectic $\mathrm{X}^{*}$.

ii) The total thermal ranges of the mesogenic phases increased with increase in the alkyloxy carbon number of the benzoic acids.

iii) The smectic $\mathrm{F}^{*}$ phase is observed in all complexes of the present homologous series, its thermal range gradually increased with the increment in the alkyloxy carbon number of the benzoic acids.

iv) The cholesteric phase originated from heptyloxy benzoic acid and malic acid hydrogen bonded complex. It exhibited a narrow thermal range in the entire homologous series except for nonyloxy carbon number where it has the largest thermal range of around $10^{\circ} \mathrm{C}$.

v) A new phase designated as smectic $X^{*}$ has been identified from octyloxy carbon number of the benzoic acids. The texture of the phase (Plate 1b) suggests it to be titled. The thermal range of this phase converged with the increment in the carbon number paving way for wide thermal range of smectic $\mathrm{C}^{*}$ phase.

vi) One of the interesting result is the increment of the thermal range of smectic $\mathrm{C}^{*}$ phase with increase in carbon number. In other words higher homologous members of the series possess high thermal range of this phase.

\section{Characterization of the Smectic X* Phase}

\subsection{Textural Observations}

A Phase transition from cholesteric to smectic $\mathrm{X}^{*}$ phase is observed in higher members (where the alkyloxy carbon number $n \geq 8$ ) of the present homologous series. The texture of the fully grown smectic $X^{*}$ phase is shown in Plate 1b. This phase starts growing from the traditional cholesteric phase (Plate 1a). Threads in the cholesteric phase transforms to canals in the smectic $\mathrm{X}^{*}$ phase. A note worthy feature is with the decreasing temperature in the smectic $X^{*}$ phase, the width of the canals is observed to increase. This result is attributed to the variation of the magnitude of helical pitch present in the smectic $X^{*}$ phase. The thermal range of this phase decreases with the increase in the alkyloxy carbon number of the benzoic acids as can be observed from the phase diagram (Fig. 2). Plate 1c depicts the transition from the smectic $\mathrm{X}^{*}$ phase to schlieren texture of smectic $\mathrm{C}^{*}$ phase.

\subsection{Nature of Transition}

From the DSC studies it is noticed that the transition from cholesteric phase to smectic $\mathrm{X}^{*}$ phase is in general of first order or weak first order. The high values of the enthalpy (Table 1) for various HBFLC complexes exhibiting this phase support the above argument. This 

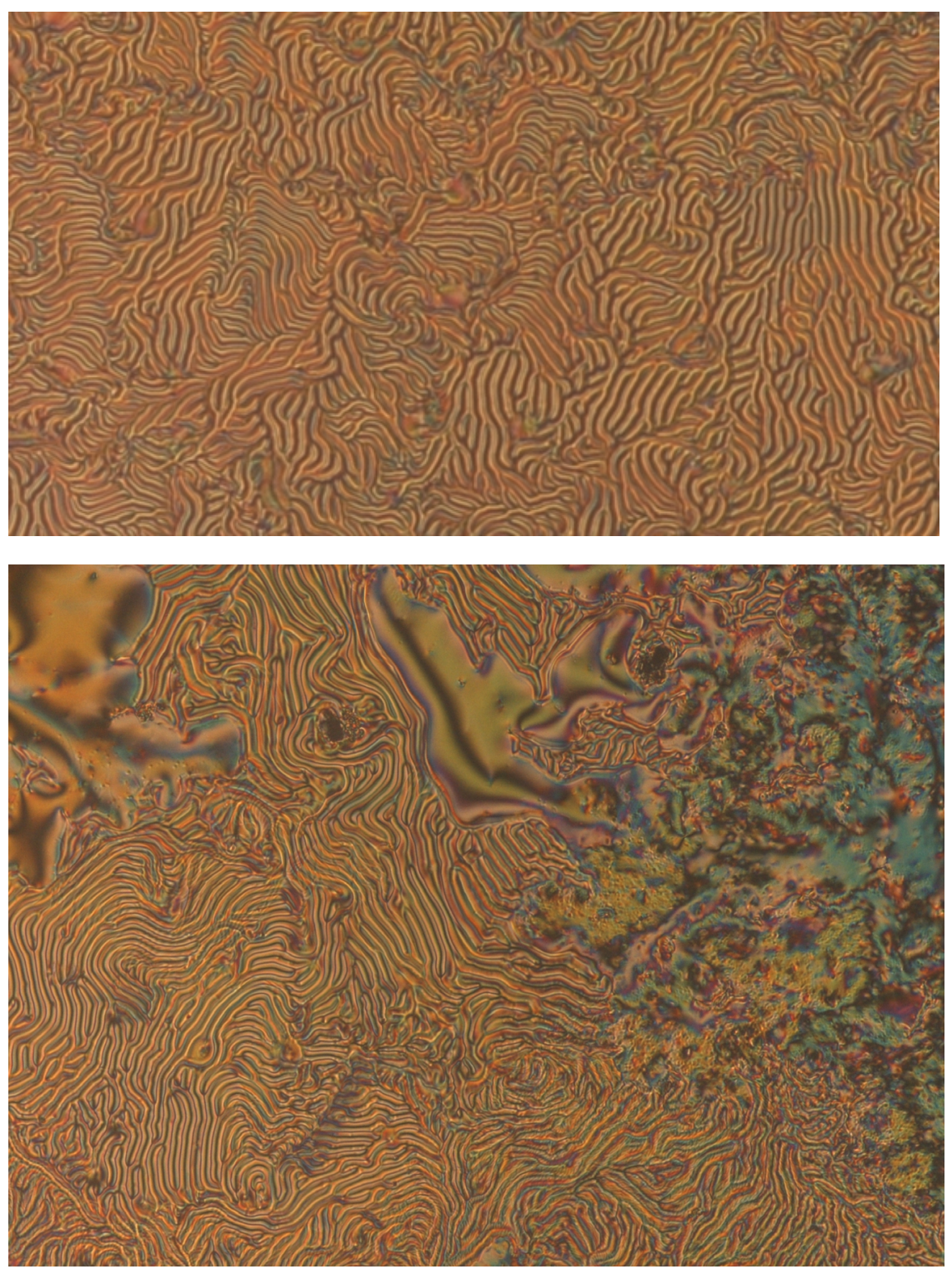

Plate $1 \mathrm{~b}$ (colour online). Fully grown smectic $\mathrm{X}^{*}$ phase of $\mathrm{MA}+8 \mathrm{BA}$
Plate 1c (colour online). Smectic $X^{*}$ to smectic $C^{*}$ phase transition in MA+8BA complex. phase is monotropic only in octyloxy benzoic acid hydrogen bonded complex while in all other HBFLC it is enantiotropic in nature. Figure 5 illustrates the phase transition, obtained by DSC, from cholesteric phase to smectic $X^{*}$ phase for various hydrogen bonded complexes. The following points can be inferred form Figure 5:

i) Basing on the enthalpy values, obtained by the peak area, the respective transition from cholesteric to smectic $X^{*}$ phase can be classified as first/weakly order. ii) Cholesteric to smectic $X^{*}$ transition temperatures shift to lower side with increase in alkyloxy carbon number of the benzoic acids; it can be argued that the increased alkyloxy carbon influences the lowering of the transition temperatures.

iii) The thermal range of cholesteric phase remains unaltered with an exception of nonyloxy benzoic acid and malic acid hydrogen bonded complex.

iv) The thermal range of smectic $X^{*}$ increases with increase in carbon number of benzoic acids. 


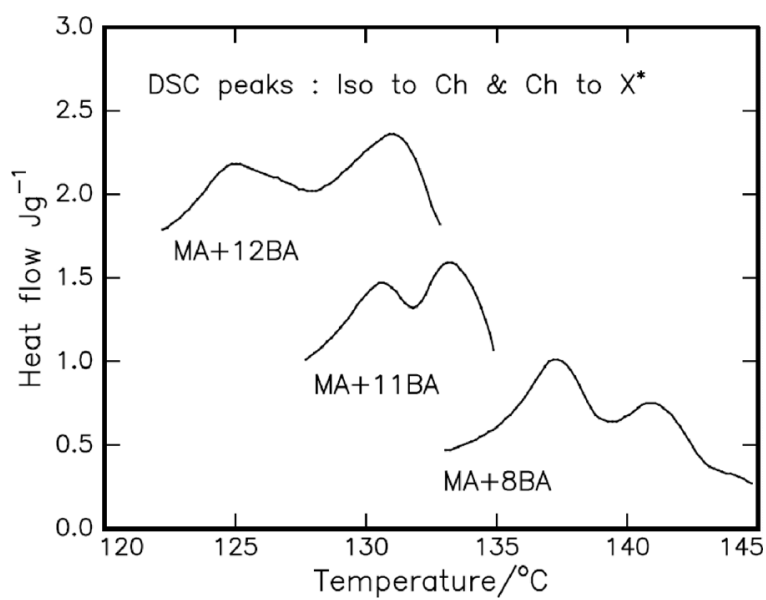

Fig. 5. DSC peaks corresponding to isotropic to cholesteric and cholesteric to smectic $\mathrm{X}^{*}$ phase transition of various members of the MA+nBA homologous series.

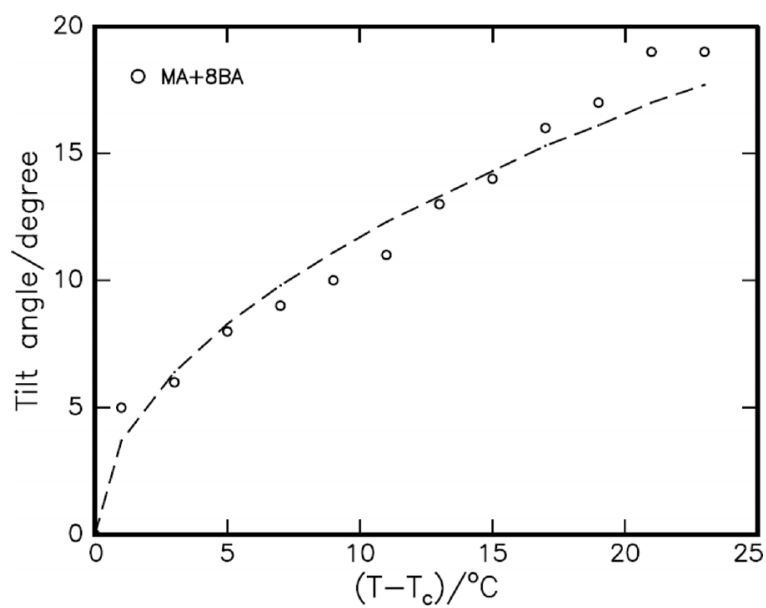

Fig. 6. Temperature variation of tilt angle in smectic $X^{*}$ phase of MA+8BA complex. Solid line denotes the power law fit.

\section{Optical Tilt Angle Measurements}

The optical tilt angle has been experimentally measured by an optical extinction method [49] in the smectic $\mathrm{X}^{*}$ phase on all the members of the present HBFLC homologous series. Figures 6 and 7 depict the variation of the optical tilt angle with the temperature for $\mathrm{MA}+8 \mathrm{BA}, \mathrm{MA}+9 \mathrm{BA}, \mathrm{MA}+10 \mathrm{BA}, \mathrm{MA}+11 \mathrm{BA}$, and $\mathrm{MA}+12 \mathrm{BA}$, respectively. In the above figures the theoretical fit obtained from the mean field theory is denoted by a solid line. From the Figures 6 and 7 it is observed that the tilt angle increases with decreasing temperature and attains a saturation value. These large

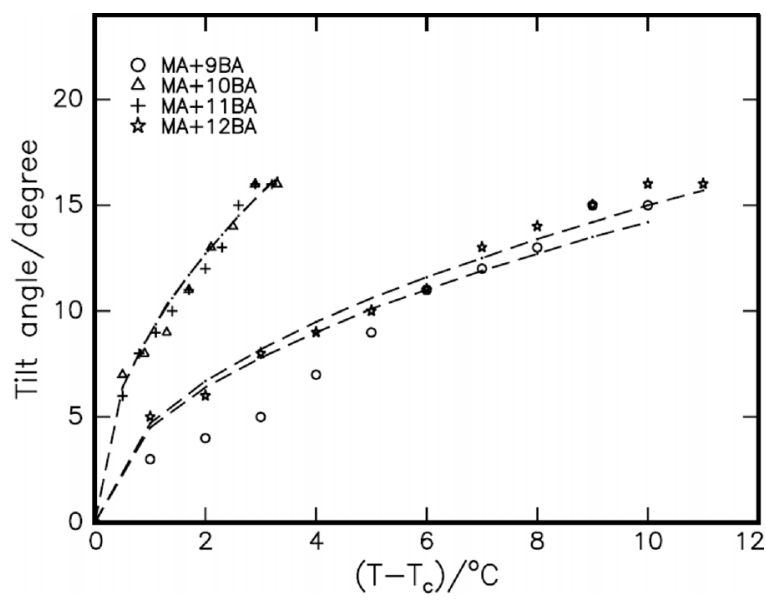

Fig. 7. Temperature variation of tilt angle in smectic $X^{*}$ phase of various homologous members of the series. Solid line denotes the power law fit.

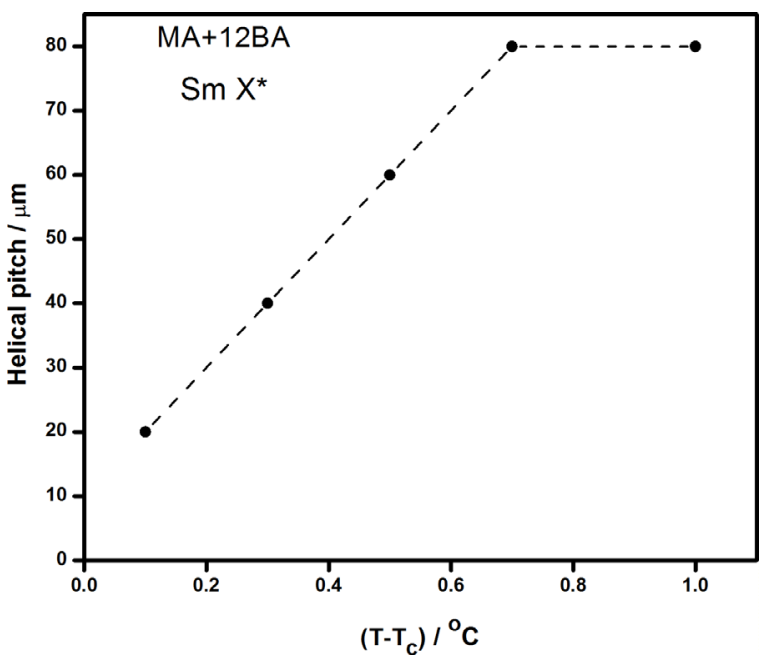

Fig. 8. Temperature variation of helix in smectic $X^{*}$ phase of MA+12BA complex.

magnitudes of the tilt angles are attributed to the direction of the soft covalent hydrogen bond interaction which spreads along molecular long axis with finite inclination [31].

The tilt angle is a primary order parameter [18] and the temperature variation is estimated by fitting the observed data of $\theta(T)$ to the relation

$$
\theta(T) \propto\left(T_{\mathrm{Ch} \mathrm{X}^{*}}-T_{\mathrm{X}^{*}}\right)^{\beta} .
$$

The value of the critical exponent $\beta$ estimated by fitting the data of $\theta(T)$ to the above equation (1) is found to be 0.50 to agree with the mean field prediction [50]. 
The solid line in Figures 6 and 7 depicts the fitted data. Further, the agreement of $\beta$ with the mean field value infers the long-range interaction of the transverse dipole moment for the stabilization of tilted smectic $\mathrm{X}^{*}$ phase.

It is noteworthy to point out that from Figures 6 and 7 it can be observed that the variation of the tilt in $\mathrm{MA}+8 \mathrm{BA}, \mathrm{MA}+9 \mathrm{BA}$, and $\mathrm{MA}+12 \mathrm{BA}$ follows one pattern while compounds MA+11BA and MA+12 BA show a different pattern of results. In the former case the thermal range of the smectic $\mathrm{X}^{*}$ phase is wide and, hence, there is a gradual increment of the tilt angle while in the latter case the narrow thermal rage of the smectic $X^{*}$ phase forces the steep increment of the tilt angle with temperature.

\section{Helical Pitch Studies}

The pitch of FLC materials is typically in the order of $1-100 \mu \mathrm{m}$ [51], whereas the thickness of one layer is of the order of $20-30 \AA$. In order to have bistable switching, the helicoidal structure has to be unwound. The most common way of doing this is to sandwich the FLC material between two conducting glass plates

[1] R. B. Meyer, L. Liebert, L. Strezelecki, and P. Keller, J. Phys. Lett. 36, 69 (1975).

[2] N. A. Clark and S. T. Lagerwall, Appl. Phys. Lett. 36, 899 (1980).

[3] G. Andersson, I. Dhal, P. Kellr, W. Kuczynski, S. T. Lagerwall, K. Skarp, and B. Stebler, Appl. Phys. Lett. 51, 640 (1987).

[4] F. Gouda, K. Skarp, and S. T. Lagerwall, Ferroelectrics 113, 165 (1991).

[5] G. Andersson, I. Dhal, W. Kuczynski, S. T. Lagerwall, K. Skarp, and B. Stebler, Ferroelectrics 84, 285 (1988).

[6] J. M. Wang, Y. J. Kim, C. J. Kim, and K. S. Kim, Ferroelectrics 277, 185 (2002)

[7] H. Aira, H. Ray, and T. Kohki, Jpn. J. Appl. Phys. 43, 6243 (2004).

[8] S. L. Wu, and C. Y. Lin, Liq Cryst. 30, 205 (2003).

[9] P. A. Kumar and V. G. K. M. Pisipati, Advc. Mater. 2, 1617 (2000).

[10] C. Kittle, Introduction to Solid State Physics, Wiley Eastern Private Limited, New Delhi 1974.

[11] G. R. Luckhurst and G.W. Gray, The Molecular Physics of Liquid Crystal, Academic Press, New York 1979.

[12] T. Niori, T. Sekine, J. Watanabe, J. Furukawa, S. W. Choi, and H. Takezoe, J. Matter. Chem. 6, 1231 (1996); ibid. 7, 1307 (1997)

[13] H. Adams, N. Braily, D. W. Bruce, R. Dhillon, in such a way that the layers are perpendicular to these structures. The helical pitch is measured by the diffraction of He-Ne red laser light on the sample, filled in a commercial cell. This method can be used for measurement of the helical pitch of limited length. For a pitch shorter than $0.8 \mu \mathrm{m}$ the diffraction ring is diffused or completely disappears.

Figure 8 illustrates the variation of the helical pitch corresponding to the smectic $\mathrm{X}^{*}$ phase of MA+12BA complex. The magnitude of the helical pitch in the smectic $\mathrm{X}^{*}$ phase is found to increase with decreasing temperature and attain a maximum value of $80 \mu \mathrm{m}$. Thus from these studies it can be concluded that the smectic $\mathrm{X}^{*}$ phase in the MA+12BA complex is smectic ordering.

\section{Acknowledgements}

One of the authors (M.L.N.M.M.) acknowledges the financial support rendered by All India Council for Technical Education, Department of Science and Technology, and Defence Research Development Organization, New Delhi. Infrastructural support provided by Bannari Amman Institute of Technology is gratefully acknowledged.

D. A. Dunmur, S.E. Hunt, E. Lalinde, A. A. Maggs, R. Orr, P. Styring, M. S. Wragg, and P.M. Maitlies, Polyhedron 7, 1861 (1988); M. A. Mikhaleva, G. A. Kolesnichenko, K. I. Rubina, Yu. Sh. Goldberg, V. A. Savelev, L. Ya. Leitis, M. V. Shimanskaya, and V. P. Mamaev, Chem. Hetro. Compound 22, 310 (1986).

[14] T. Kato and J. M. J. Frechet, J. Am. Chem. Soc. 111, 8533 (1989); T. Kato, Hydrogen Bonded Liquid Crystals: Moleculare Self-Assembly for Dynamically Functional Materials, Springer, Heidelberg 2000.

[15] H. Kihara, T. Kato, T. Uryu, S. Ujiie, U. Kumar, J. M. J. Frechet, D. W. Bruce, and J. D. Price, Liq. Cryst. 21, 25 (1996); M. Parra, P. Hidalgo, and J. Alderete, Liq. Cryst. 32, 449 (2005).

[16] H. R. Brand, P.E. Cladis, and H. Pleiner, Macro. Mol. 25, 7223 (1992); A. G. Cook, U. Baumeister, and C. Tschierske, J. Mater. Chem. 15, 1708 (2005).

[17] J. W. Goodby, R. Blinc, N. A. Clark, S. T. Lagerwall, S. A. Osipov, S. A. Pikin, T. Sakurai, Y. Yoshino, and B. Zecks, Ferro Electric Liquid Crystal, Principles, Properties, and Applications, Gorden and Breech Press, Philadalphia 1991.

[18] P. G. de Gennes, The Physics of Liquid Crystals, Oxford Press, London 1974.

[19] B. Sreedevi, P. V. Chalapathi, M. Srinivasulu, V. G. K. M. Pisipati, and D. M. Potukuchi, Liq. Cryst. 31, 303 (2004). 
1164 V. N. Vijayakumar and M. L. N. Madhu Mohan · Self Assembly Systems of Malic Acid and Alkyloxy Benzoic Acids

[20] P. Swathi, P. A. Kumar, V. G. K. M.Pisipati, A. V. Rajeswari, S. Sreehari Sastry, and P. Narayana Murty, Z. Naturforsch. 57a, 797 (2002).

[21] C. Noot, S. P. Perkins, and H. J. Coles, Ferroelectrics 244, 331 (2000).

[22] P. Swathi, P. A. Kumar, and V. G. K. M. Pisipati, Z. Naturforsch. 56a, 691 (2001).

[23] P. A. Kumar, V. G. K. M.Pisipati, A. V. Rajeswari, and S. Sreehari Sastry, Z. Naturforsch. 57a, 184 (2002).

[24] M. L. N. Madhu Mohan, B. Arunachalam, and C. Arravindh Sankar, Metal Mater. Trans. A 39, 1192 (2008).

[25] M. L. N. Madhu Mohan and B. Arunachalam, Z. Naturforsch. 63a, 435 (2008).

[26] M. L. N. Madhu Mohan and V. G. K. M. Pisipati, Liq. Cryst. 26, 1609 (2000).

[27] P. Letellier, D. E. Ewing, J. W. Goodby, J. Haley, S. M. Kelly, and G. Mackenzie, Liq. Cryst. 22, 609 (1997).

[28] P. A. Kumar, M. Srinivasulu, and V. G. K. M. Pisipati, Liq. Cryst. 26, 1339 (1999).

[29] P. Rudquist, E. Korblova， D. M. Walba， R. Shao, N. A. Clark, and J.E. Maclennan, Liq. Cryst. 26, 1555 (1999).

[30] M. Srinivasulu, P. V. V. Satyanarayana, P. A. Kumarand, and V. G. K. M. Pisipati, Liq. Cryst. 28, 132 (2001).

[31] E. B. Barmatov, A. Bobrovsky, M. V. Barmatova, and V. P. Shibaev, Liq. Cryst. 26, 581 (1999).

[32] Z. Sideratou, D. Tsiourvas, C.M. Paleos, and A. Skoulios, Liq. Cryst. 22, 51 (1997).

[33] T. Chitravel, M.L. N. Madhu Mohan, V. Krishnakumar, Mol. Cryst. Liq. Cryst. 493, 17 (2008).

[34] V. N. Vijayakumar and M. L. N. Madhu Mohan, Braz. J. Phys. 39, 677 (2009).

[35] V. N. Vijayakumar and M. L. N. Madhu Mohan, Solid State Commun. 149, 2090 (2009).
[36] V.N. Vijayakumar, K. Murugadass, and M.L.N. Madhu Mohan, Mol. Cryst. Liq. Cryst. 515, 37 (2009).

[37] V. N. Vijayakumar and M. L. N. Madhu Mohan, Braz. J. Phys. 39, 601 (2009).

[38] V. N. Vijayakumar and M. L. N. Madhu Mohan, Ferroelectrics 392, 81 (2009).

[39] P. A. Kumar, M. L. N. Madhu Mohan, and V. G. K. M. Pisipati, Liq. Cryst. 27, 1533 (2000).

[40] V. N. Vijayakumar and M. L. N. Madhu Mohan, Ferroelectrics (in press).

[41] M. L. N. Madhu Mohan, P. A. Kumar, B. V. S. Goud, and V.G. K. M. Pisipati, Mater. Res. Bull. 34, 2167 (1999).

[42] M. L. N. Madhu Mohan, P. A. Kumar, and V. G. K. M. Pisipati, Ferroelectrics, 227, 105 (1999).

[43] M. L. N. Madhu Mohan, D.M. Potukuchi, and V. G. K. M. Pisipati, Mol. Cryst. Liq. Cryst. 325, 127 (1998).

[44] V. N. Vijayakumar and M.L.N. Madhu Mohan, Solid State Sci. (in press), DOI: 10.1016/j.solidstatesciences.2009.12.012.

[45] V.N. Vijayakumar and M. L. N. Madhu Mohan, J. Opto. Adv. Matter. 11, 1139 (2009).

[46] M. L. N. Madhu Mohan, P. A. Kumar, and V. G. K. M. Pisipati, Mol. Crys. Liq. Cryst. 366, 431 (2001).

[47] G. W. Gray and J. W. G. Goodby, Smectic Liquid Crystals: Textures and Structures, Leonard Hill, London 1984.

[48] K. Nakamoto, Infrared and Raman Spectra of Inorganic and Co-ordination Compounds, Interscience, New York 1978.

[49] J. S. Patel and J. W. Goodby, Mol. Crys. Liq. Cryst. 144, 117, (1987).

[50] H. E. Stanley, Introduction to phase transition and critical phenomena, Clarendon Press, New York 1971.

[51] R. Karapinar, Turk. J. Phys. 24, 115 (2000). 